DOI: http://dx.doi.org/10.22484/2177-5788.2017v43n1p169-192

\title{
O "jornalismo de guerra" na configuração da narrativa do noticiário em tempos de impeachment
}

\author{
Eduardo Luiz Correia
}

Resumo: No cenário atual de disputas políticas no Brasil, o termo "jornalismo de guerra" passou a ser utilizado para caracterizar certo tipo de cobertura da imprensa praticado por alguns veículos de referência. A proposta deste artigo é refletir sobre a pertinência do uso do termo diante de determinados acontecimentos, assim como analisar suas estratégias discursivas. Neste caso, por meio da análise da narrativa, a intenção é demonstrar como o jornal O Globo recorreu a esta modalidade de cobertura na narrativa do impeachment de Dilma Rousseff. Para tanto, foram analisadas as edições de março e abril de 2016, período preliminar à votação da aceitação da abertura do processo de impedimento da presidente. A hipótese é a de que o jornal, em momentos determinados, intensificou o noticiário negativamente contra o governo de então e seus aliados tendo a chamada Operação Lava-Jato como agente condutor da narrativa.

Palavras-chave: Análise da narrativa. Jornalismo de guerra. Impeachment. Jornal O Globo.

\section{"War journalism" in the configuration of the news in times of impeachment}

Abstract: In the current political scenario in Brazil, the term "war journalism" began to be used to characterize a certain type of press coverage practiced by some mainstream publications. The aim of this article is to evaluate the relevance of using the term in the face of recent events, as well as to analyze its discursive strategies. Through narrative analysis, the objective is to investigate the Brazilian daily $O$ Globo former president Dilma Rousseff impeachment's coverage. Corpus comprises the editions of the months of March and April, 2016, i.e., the period immediately before the impeachment process. The hypothesis is that the newspaper, at certain moments, has intensified the negatively coverage in detriment of the official and governementallies'versions, having the so-called Lava-Jato Operation as the guiding agent of the narrative.

Keywords: Narrative analysis. War journalism. Impeachment. Journal - O Globo. 
O mês de agosto registra fatos marcantes na política brasileira: suicídio de Getúlio Vargas (1954), renúncia de Jânio Quadros (1961) e a morte de Juscelino Kubistchek num acidente automobilístico (1976). Mais recentemente, outro acontecimento somou-se às efemérides do mês: O de "31 de agosto de 2016", data a marcar a História do país com o impedimento de Dilma Rousseff, do Partido dos Trabalhadores - PT, frente ao seu cargo de presidente da República. Rousseff venceu as eleições em 2014 (sendo reeleita no mandato), sob margem apertada de votos - 51,6\% dos votos válidos contra 48,3\% do candidato derrotado Aécio Neves, do PSDB.

Impedimento, ou impeachment, cujo desenrolar trouxe o jornalismo ao centro da discussão, dado seu papel estratégico na arena discursiva contemporânea da História do presente. Em particular, sob a designação de alguns críticos como "jornalismo de guerra", epíteto utilizado para definir o que seria um comportamento pró ativo da imprensa na desqualificação de desafetos ou na construção de sentidos para determinada causa de seu interesse.

A proposta aqui é refletir sobre a pertinência do uso da expressão e a prática deste chamado "jornalismo de guerra" na cena política brasileira pela perspectiva da cobertura da imprensa sobre o acontecimento noticioso do impedimento de Rousseff. Mais diretamente no que diz respeito ao processo de formação narrativa dos episódios que culminaram no desfecho daquele acontecimento. O corpus da análise será as edições do jornal O Globo, de março e abril de 2016 - período que compreende a véspera e o momento imediatamente seguinte após a aceitação do pedido de impeachment pela Câmara dos Deputados, em 16 de abril daquele ano ${ }^{1}$. Os métodos de trabalho serão os da análise pragmática da narrativa, concebida em seu modelo matricial por Luiz Gonzaga Motta. E tendo também a contribuição epistemológica de outros narratólogos e das teorias construcionistas do jornalismo.

A opção pelo método da análise pragmática da narrativa deve-se a possibilidade de extrair, a partir dos enunciados das notícias encadeados em sequência lógica (temática e temporal), uma perspectiva ampliada do acontecimento, assim como apreender as estratégias textuais do narrador para a formação de sentidos que almeja. Pois, como aponta Motta (2007, p. 144), "quando o narrador configura um discurso na sua forma narrativa, ele introduz uma força ilocutiva

\footnotetext{
${ }^{1}$ Com a aprovação pela Câmara, o passo seguinte foi a apreciação do pedido de impeachment no Senado Federal, que culminou no afastamento de Dilma Rousseff em agosto e a posse do vice Michel Temer como presidente da República.
} 
responsável pelos efeitos que vai gerar no seu destinatário". Formação de sentidos promovida a partir de uma estratégia organizadora da narrativa, sustentada por uma retórica configurada para dar apoio às intencionalidades do autor.

A escolha de $O$ Globo como corpus justifica-se por ser um dos principais jornais de referência no país ${ }^{2}$, cujo potencial de força perlocutiva extrapola o objeto impresso pautando os demais veículos de comunicação. O jornal, portanto, abriga considerável poder simbólico no campo da comunicação, assim como nos político e econômico. Isso também por, graças ao arranjo empresarial do seu conglomerado midiático, permitir que posicionamentos afirmados em editoriais, pelos articulistas e no corpo das reportagens sejam reproduzidos, e potencializados discursivamente, em outros meios de maior alcance filiados ao próprio complexo informativo do grupo empresarial, como a televisão (aberta e a cabo), rádio e internet. E, por fim, pelo motivo de os próprios protagonistas do enredo do impeachment criticarem o então chamado "jornalismo de guerra" que teria sido adotado pela imprensa, incluindo a Rede Globo. Rousseff, por exemplo, foi pontual em caracterizar a cobertura de O Globo como "jornalismo de guerra".

Desta forma, a proposta de análise do corpus parte das edições impressas de O Globo no período mencionado, traçando uma linha cronológica das coberturas, correlacionando-as em seu conjunto num discurso como um todo. Ou seja, trata-se de observar o comportamento da publicação em sua totalidade editorial, considerando-se recursos retóricos e dêiticos. Os elementos paratextuais da narrativa, assim como também as implicaturas a compor todo um mosaico narrativo reconfigurado. Isso pois, "as implicaturas não formam parte de um sentido literal de um enunciado, mas se produzem pela combinação do sentido literal e do contexto" (MOTTA, 2006, p. 20).

Faz-se, desta forma, de um exercício de interpretação da narrativa na linha proposta por Thompson (2009), a da hermenêutica de profundidade (depthhermeneutics), que leva em consideração estarem as "formas simbólicas significativas estruturadas internamente" no campoobjeto da pesquisa. E que possibilita mostrar como "diferentes enfoques da análise da cultura,

\footnotetext{
${ }^{2}$ Conforme o Instituto Verificador de Circulação (IVC), o jornal O Globo é o segundo maior do país, com tiragem média, no primeiro semestre em 2016, de 291.909 exemplares. Atrás da Folha de São Paulo, o de maior circulação registrada, com a média de 304.594 exemplares diários no mesmo período (https://www.ivcbrasil.org.br)
} 
ideologia e comunicação de massa podem ser relacionados de uma maneira sistemática". Isso de modo a "iluminar diferentes aspectos desses fenômenos multifacetados". Em suma, uma análise com os instrumentos de investigação da análise pragmática da narrativa, sob a égide da hermenêutica de profundidade (termo também utilizado por Paul Ricoeur) de Thompson.

Algumas reflexões apontam a parcialidade na cobertura da imprensa sobre o processo de impeachment em 2016. Oliveira (2016) demonstra como as manifestações pelo e contra o impedimento da presidente Dilma Rousseff foram, editorialmente, desequilibradas em favor das primeiras. O linguista Van Dijk (2016) cita que a "mídia usou seu poder para legitimar o golpe". Bentes (2016), por seu lado, afirma que "a tempestade midiática foi calibrada e modulada, sua velocidade e intensidade foi gerida, sendo desacelerada a partir de 13 de maio de 2016, com Dilma já afastada pelo rito do impeachment".

A intenção desta investigação, ressalte-se, não é conferir a parcialidade (ou não) da mídia, comparando-se coberturas de agentes ou episódios feitas a um campo político em detrimento de outro. Mas verificar o comportamento da imprensa, no caso representada por O Globo como objeto, em seus aspectos de relevância e saliência dados ao noticiário, tendo sob baliza de interpretação o termo "jornalismo de guerra".

A expressão "jornalismo de guerra" não se restringe à classificação de determinado padrão de cobertura desenvolvido apenas no Brasil. Julian Blanck, editor chefe e colunista político do jornal diário argentino Clarín, admitiu em entrevista concedida em 19 de julho de 2016, ao La Isquierda Diario e reproduzida pela edição brasileira digital desse diário, que sua publicação praticou tal tipo de cobertura contra o mandato da ex-presidente Cristina Kirschner. Os Kirschner, primeiro na gestão do marido Néstor (2003-2007) e depois durante os dois governos de Cristina, enfrentaram forte oposição do jornal argentino, principalmente após a lei de regulamentação (antimonopolista) dos meios de comunicação. Legislação que buscou desconcentrar aos conglomerados midiáticos no país vizinho. Entre os quais, o Clarín.

No Brasil, Rousseff (2017, quase um ano após perder o cargo de presidente da República, utilizou a expressão ao postar no Blog da Dilma (www.dilma.com.br) uma crítica ao desequilíbrio da cobertura midiática, feita com base em levantamento do site noticioso de política (Poder 360) sobre os escândalos de corrupção da chamada Operação Lava-Jato, do Ministério Público. Na ocasião, ela disse que "o jornalismo de guerra da Rede Globo tem sido a maior arma contra a 
democracia e o desenvolvimento do país e os direitos da nossa população. A Rede Globo insiste nas suas tentativas de manipular a opinião do povo brasileiro".

Este "jornalismo de guerra" promovido ao longo dos anos recentes teria por característica narrativa, como num conflito de campo real, alterar fases de maior ou menor intensidade em sua agressividade editorial, como sinalizou Bentes. Nesta reflexão, a hipótese de fundo é a de que: em primeiro lugar, verificando-se ter o acontecimento jornalístico do impeachment de Rousseff abrigado efetivamente componentes desta modalidade de cobertura; daí investigar os esforços da imprensa em qualificar negativamente o então governo partindo de várias frentes, em consonância e complementares, de modo a comprometer algumas premissas basilares da prática do considerado bom jornalismo. Pressupostos ontológicos da atividade profissional como a busca pela objetividade, equilíbrio, imparcialidade e neutralidade na prática jornalística.

Numa analogia com a História, é como comparar o comportamento da imprensa ao da estratagema militar da Alemanha nazista, na II Guerra Mundial, conhecida como "blitzkrieg" (guerra-relâmpago) - uma artimanha belicista dos alemães, a qual, em resumo, pode ser definida como ataques rápidos e sem aviso, em várias frentes, de modo a desorganizar as linhas de defesa do inimigo. Assim, admitindo-se uma "blitzkrieg" narrativa levada a cabo por $O$ Globo, o "ataque" noticioso contra o governo e seus aliados deu-se também por diversos flancos abertos contra a administração de Dilma Rousseff, tendo efeitos colaterais significativos também ao Partido dos Trabalhadores e lideranças políticas e empresariais a ele ligadas.

Essa configuração narrativa negativa, confeccionada com base na cobertura do jornal, teria sua tessitura da intriga tramada pelo arranjo complementar discursivo que é amarrado, principalmente, pelas notícias de política e de economia. E tendo seus sentidos acentuados em editorias de colunas de opinião. Tais relatos, vistos sob uma percepção atomizada, pouco significam na formação de sentidos narrativos. Porém, percebidos em conjunto, articulados, conseguem dar uma unidade de direção a moldar os sentidos da narração em determinadas arenas discursivas.

A partir das notícias esparsas ou aparentemente desconexas da cobertura diária é possível compreender a formação mais ampla da narrativa de um acontecimento noticioso pelos seus núcleos temáticos, ou actantes, na definição de Greimas. Esses actantesmoldam, em conjunto, os sentidos narrativos promovidos pelas classes de atores, as responsáveis pelos atos 
ativos ou passivos no interior da narrativa. Formam, assim, as narrativas "encaixadas no centro de uma intriga englobante" (REUTER, 2007, p. 85). Intriga englobante que pode ser tomada como o principal eixo da narração, mas a carregar vários outros níveis narrativos. No caso específico aqui, a intriga englobante tomada pela cobertura do mega-acontecimento do impeachment da presidente da República e constituída pelas suas narrativas secundárias, estando elas nos atos de fala surgidos no mosaico noticioso da arena discursiva que é o jornal. E em toda sua rede comunicacional, por extensão.

Tais narrativas encaixadas, a se somar num todo narrativo (e, portanto, também discursivo), formam, conforme seus graus de saliência e relevância, a ofensiva noticiosa promovida contra os agentes detentores do poder até então, juntamente com aqueles que gravitariam em seu redor. Tal ofensiva narrativa foi construída a partir de várias frentes, conduzidas por diversos narradores-jornalistas, tendo seu momento crucial às vésperas da votação da aceitação ou não do pedido de impedimento pela Câmara dos Deputados.

Para mapear os núcleos temáticos da narrativa no período delimitado para esta investigação foram analisadas 724 páginas de $O$ Globo (355 em março/369 em abril), publicadas nos cadernos de política (O País) e o de economia. Conforme a amostragem, podese perceber a destinação de maiores espaços editoriais em determinados momentos do megaacontecimento, como na manifestação "Fora Dilma" (13 de março), com estimativas de participação de mais de 3,4 milhões de pessoas em diversas cidades do país, segundo levantamento do jornal. Também quando Rousseff movimentou-se para nomear o ex-presidente Luís Inácio Lula da Silva para a Casa Civil de seu governo (com a divulgação por parte do juiz Sérgio Moro, da $1^{\mathrm{a}}$ Vara de Curitiba, do Paraná, do controverso "grampo" telefônico entre Rousseff e Lula). E um mês depois, na votação do pedido de aceitação do processo de impeachment pela Câmara dos Deputados (17 de abril).

Foram episódios decisivos da narrativa englobante, com pontos de inflexão importantes no desenrolar do caso. A esses três momentos somam-se inúmeros outros, que foram "encaixando-se" ao eixo principal da história. Ao longo do período analisado, é possível estabelecer um fio narrativo a amarrar todas as micro-narrativas, ou narrativas secundárias, conforme se observa pelos chamados "chapéus" - expressão, no jargão jornalístico, acima do título para sinalizar o tema da notícia. 
Ao longo da amostra, verificou-se terem sido publicados, com maior frequência, 12 destes recursos gráficos diferentes ao alto das páginas de política ou economia. A saber: "escândalos em série", "crise política", "recessão histórica", "ecos da Lava-Jato", "perdas em série", "a conta da crise", "desemprego recorde", "crise sem fim", "encruzilhada petista", "efeitos da crise", "batalha do impeachment", "a guerra do impeachment" e, por fim, "efeitos do impeachment". Todos negativos aos detentores do poder oficial até então, sejam pessoas, gestões governamentais e/ou partidos políticos.

Dêiticos que, por si, sinalizam para o quadro negativo do cenário político e econômico naquele momento. Embora possa alegar-se que a publicação procurou apenas retratar a situação do Brasil daqueles dias, é possível notar que há ao longo da cobertura um esforço em salientar, e dar relevância, a certos aspectos prejudiciais ao grupo instalado no comando do país e a outros favoráveis àqueles dedicados a tomar o poder. Não somente pela publicação das chamadas hardnews (notícias factuais do dia-a-dia), mas também por meio das opiniões contidas em editoriais e nas colunas dos articulistas, majoritamente favoráveis à substituição da presidente. De certo modo, são nesses espaços opinativos nos quais o "jornalismo de guerra" carrega sua artilharia de modo perceptível e, retoricamente, mais intenso.

O próprio enquadramento noticioso, segundo Motta (2010), feito pelo jornal diante de conflitos políticos na sociedade costuma apropriar-se de representações dramáticas e lúdicas, presentes na cultura compartida entre leitor-receptor e jornalista-narrador. Trata-se de um dispositivo retórico a facilitar o entendimento dos complexos jogos em disputa no intrincado campo da política, presentes também em charges, títulos, textos, infografias e legendas de fotos. De modo a formar um todo discursivo a transformar o jornal numa espécie de narrador singularcoletivo, conforme o termo cunhado por Kosseleck (2006). Ou seja, a publicação abriga em si as várias singularidades do acontecimento centrando-as sobre um eixo definidor comum que, reconfigurado, torna-se um condutor singular mas de um coletivo de vozes unidirecionais na reprodução noticiosa do acontecimento.

Sob os "chapéus" elencados pelo jornal para sinalizar o tema das matérias, tem-se que toda a cobertura do acontecimento do impeachment de Rousseff organiza-se sob tais frames narrativos(enquadramentos) numa conformação desfavorável para a então governante do país e seus aliados políticos. Por exemplo, um dos elementos narrativos perdidos por Rousseff e seu grupo nas disputas por sentidos foi na tentativa de definir semanticamente o processo de 
impedimento como um "golpe" - termo que na política sugere um ardil, um ato desonesto fora das regras do jogo democrático. Conforme Bobbio et al. (2003), "são mudanças no governo feitas na base da violação da Constituição legal do Estado, normalmente, de forma violenta, por parte dos detentores do poder".

Assim que a ex-presidente Dilma Rousseff passou a qualificar publicamente o processo de impeachment como um "golpe", o jornal assumiu editorialmente sua discordância ao uso do termo, no que foi seguido também por seus articulistas (Quadro I). A postura legalista do jornal baseou-se essencialmente no aspecto de que o instituto do impedimento consta da Constituição Federal, sem entrar no mérito da forma como foi conduzido pelo então presidente da Câmara, deputado Eduardo Cunha (PMDB). Ou se houve, de fato, crime de responsabilidade praticado pela principal governante. Dilma Rousseff perdeu o cargo por ter cometido, segundo decisão do Parlamento, as chamadas "pedaladas fiscais", que são manobras contábeis de modo a mascarar o orçamento da União. Tese controversa, cuja defesa da presidente alegava fundamentalmente que tal procedimento já teria sido utilizado por vários outros mandatários, aos níveis federal e estaduais, e seu cometimento não conferiria em si um crime de responsabilidade da governante.

Nas edições de março e abril (61 no total), foram nove editoriais (os espaços da voz institucional do jornal, a coluna “Opinião") voltados à desqualificação do termo "golpe" e das razões que poderiam denominar desta maneira o processo de impedimento presidencial. No sentido político, o embate em torno da denominação do acontecimento é fundamental por razões, inclusive, geopolíticas. Caracterizar o afastamento de um presidente como um golpe parlamentar prejudicaria as relações internacionais com outros países, sendo que a falta de legitimidade conferida por um processo viciado também colocaria em questão quaisquer medidas administrativas internas tomadas pelo sucessor da presidente. No caso, seu vicepresidente Michel Temer, do PMDB. Por sua vez, o impeachment sendo efetivamente caracterizado com um ato dentro da legalidade institucional contribuiria para a legitimidade do novo governo.

Quadro I - Editoriais “golpe” $x$ impeachment.

$\begin{array}{lllll}\text { data } & \text { Pág. } & \text { Coluna/autor } & \text { Título } & \text { Trecho } \\ 24.03 & \text { p. } 18 & \begin{array}{l}\text { Opinião } \\ \text { (editorial) }\end{array} & \begin{array}{l}\text { Dilma radicaliza e fala de um país } \\ \text { imaginário }\end{array} & \begin{array}{l}\text { "O Brasil de 2016 não é o de 61, e } \\ \text { por isso não existe golpe em curso, } \\ \text { como demonstrado pelo }\end{array}\end{array}$




\begin{tabular}{|c|c|c|c|c|}
\hline & & & & $\begin{array}{l}\text { funcionamento institucional do } \\
\text { Congresso e do Judiciário". }\end{array}$ \\
\hline 34.03 & p. 16 & $\begin{array}{l}\text { Opinião } \\
\text { (editorial) }\end{array}$ & A farsa do "golpe" & $\begin{array}{l}\text { "Construída pelo lulopetismo, } \\
\text { aceitar a tese de que seria ilegal o } \\
\text { afastamento de Dilma é admitir que } \\
\text { o STF participaria de uma ação de } \\
\text { cunho político contra princípios da } \\
\text { Constituição". }\end{array}$ \\
\hline 12.04 & p. 18 & $\begin{array}{l}\text { Opinião } \\
\text { (editorial) }\end{array}$ & $\begin{array}{l}\text { Dentro da lei, dentro da } \\
\text { Constituição }\end{array}$ & $\begin{array}{l}\text { "O país vive a sua maior crise } \\
\text { política desde a democratização, as } \\
\text { paixões estão à flor da pele, mas } \\
\text { ninguém vislumbra uma saída que } \\
\text { seja à margem da Carta". }\end{array}$ \\
\hline 16.04 & p. 4 & $\begin{array}{l}\text { Opinião } \\
\text { (editorial) }\end{array}$ & $\begin{array}{l}\text { STF acerta ao manter tramitação } \\
\text { do impeachment }\end{array}$ & $\begin{array}{l}\text { "Supremo agiu de maneira correta } \\
\text { ao não intervir no processo de } \\
\text { impedimento da presidente, uma } \\
\text { questão política que não será } \\
\text { julgada na Justiça comum". }\end{array}$ \\
\hline 17.04 & p. 14 & $\begin{array}{l}\text { Opinião } \\
\text { (editorial) }\end{array}$ & Não vai mesmo ter golpe & $\begin{array}{l}\text { "Importante é que, seja ou não } \\
\text { aprovada a admissibilidade do } \\
\text { processo de impeachment da } \\
\text { presidente Dilma, tudo transcorre } \\
\text { sem quebra da ordem institucional". }\end{array}$ \\
\hline 20.04 & p. 20 & $\begin{array}{l}\text { Opinião } \\
\text { (editorial) }\end{array}$ & $\begin{array}{l}\text { Bolivarianos e Dilma se isolam } \\
\text { na farsa do golpe }\end{array}$ & $\begin{array}{l}\text { "PT e governo conseguiram } \\
\text { propagar a ideia de uma ruptura de } \\
\text { ordem institucional, num ato típico } \\
\text { de governos chavistas quando são } \\
\text { confrontados dentro da Lei". }\end{array}$ \\
\hline 21.04 & p. 18 & $\begin{array}{l}\text { Opinião } \\
\text { (editorial) }\end{array}$ & $\begin{array}{l}\text { Dilma põe interesses pessoais } \\
\text { e do PT acima do País }\end{array}$ & $\begin{array}{l}\text { "Presidente usa prerrogativa do } \\
\text { cargo para, da tribuna da ONU, } \\
\text { denunciar um golpe inexistente e, } \\
\text { com isso, mancha a imagem do } \\
\text { Congresso e do Supremo". }\end{array}$ \\
\hline 25.04 & p. 13 & $\begin{array}{l}\text { Opinião } \\
\text { (editorial) }\end{array}$ & A mentira do golpe & $\begin{array}{l}\text { "A falsa narrativa é na verdade o } \\
\text { maior de todos os golpes que } \\
\text { poderiam ser desferidos contra o } \\
\text { regime democrático brasileiro". }\end{array}$ \\
\hline 30.04 & p. 18 & $\begin{array}{l}\text { Opinião } \\
\text { (editorial) }\end{array}$ & $\begin{array}{l}\text { O verdadeiro golpe é o das } \\
\text { Diretas Já }\end{array}$ & $\begin{array}{l}\text { "A manobra, de origem petista, } \\
\text { esbarra em obstáculos } \\
\text { intransponíveis, como a necessidade } \\
\text { de Temer renunciar e sua própria } \\
\text { inconstitucionalidade". }\end{array}$ \\
\hline
\end{tabular}


A disputa semântica em torno da qualificação do afastamento da presidente do cargo foi também intensa nos textos dos articulistas do jornal. Os dois principais (Merval Pereira, na política; Míriam Leitão, na economia) alternaram-se na defesa da legalidade do impeachment (Quadro II). Em sete colunas, a dupla de jornalistas publicou no período desta análise seus textos sobre o tema na mesma linha editorial das da coluna Opinião (editorial).

Quadro II - Colunistas titulares - Merval Pereira e Miriam Leitão.

\begin{tabular}{|c|c|c|c|c|}
\hline Data & Pág. & Coluna/autor & título & trecho \\
\hline 23.03 & p. 4 & Merval Pereira & Samba do político doido & $\begin{array}{l}\text { "Itamaraty enviou a embaixadas } \\
\text { circulares pra alertar de 'golpe'". }\end{array}$ \\
\hline 27.03 & p. 4 & Merval Pereira & Narrativa ridícula & $\begin{array}{l}\text { "A tal 'narrativa' que os que ainda } \\
\text { apoiam o governo de Dilma Rousseff } \\
\text { tentam estabelecer como verdade, de } \\
\text { que o impeachment a ser votado no } \\
\text { Congresso é um golpe judicial, sem } \\
\text { tanques nas ruas, não tem encontrado } \\
\text { muita receptividade fora do próprio } \\
\text { círculo de convertidos..." }\end{array}$ \\
\hline 30.03 & p. 4 & Merval Pereira & "Não vai ter golpe" & $\begin{array}{l}\text { "Como se vê, há na proposta um } \\
\text { golpe embutido, da mesma qualidade } \\
\text { da ideia de implantar-se o } \\
\text { parlamentarismo } \\
\text { semiparlamentarismo, em meio ao } \\
\text { mandato em curso. Não, não vai ter } \\
\text { golpe". }\end{array}$ \\
\hline 31.03 & p. 18 & Míriam Leitão & As ameaças de Dilma & $\begin{array}{l}\text { "A presidente Dilma Rousseff, ao } \\
\text { falar no Palácio do Planalto que se } \\
\text { prepara um golpe, deu a senha para } \\
\text { que a farsa fosse utilizada em defesa } \\
\text { do governo..." }\end{array}$ \\
\hline 19.04 & p. 4 & Merval Pereira & Ameaça à democracia & $\begin{array}{l}\text { "A presidente Dilma assumiu ontem } \\
\text { formalmente a tese do golpe } \\
\text { parlamentar que o advogado-geral da } \\
\text { União, José Eduardo Cardoso, vem } \\
\text { defendendo temerariamente há } \\
\text { algum tempo. Se na boa de Cardoso } \\
\text { essa afirmação já era potencialmente } \\
\text { perigosa, na da presidente } \\
\text { transforma-se em ameaça à } \\
\text { democracia". }\end{array}$ \\
\hline 21.04 & p. 22 & Míriam Leitão & O risco da tese falsa & $\begin{array}{l}\text { "...Quando a presidente Dilma usa } \\
\text { como estratégia dizer que há um } \\
\text { golpe sendo executado, ela joga um }\end{array}$ \\
\hline
\end{tabular}

REU, Sorocaba, SP, v. 43, n. 1, p. 169 - 192, jun. 2017 


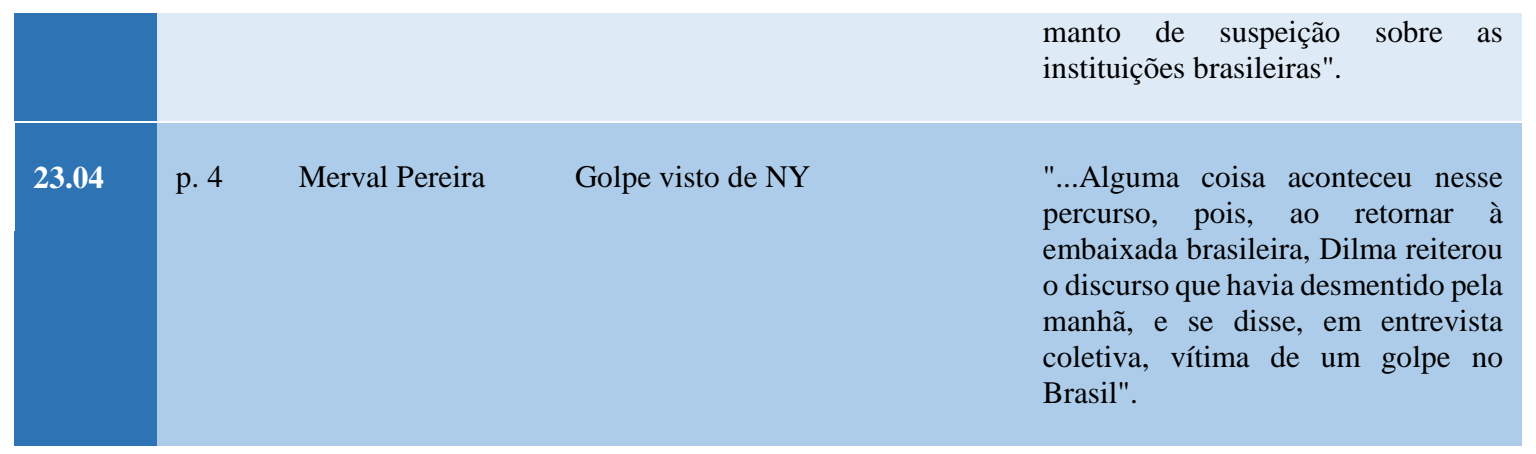

Outra frente na ofensiva em defesa do termo impeachment partiu de diversos articulistas, com presenças periódicas semanais ou quinzenais, e colaboradores esporádicos. Nesta senda foram nove artigos, produzidos por autores diferentes, em defesa do suposto legalismo do movimento de afastamento da presidente da República. Registre-se que, no mesmo período, não se localiza nenhum texto cujo apelo favorável ao termo do "golpe" tenha sido publicado nestes espaços de opinião considerados editorialmente nobres. Em todas as situações, os autores, que vão de críticos de música, economistas liberais, cineastas passando por um senador da oposição, revelam-se francamente contrária ao uso do termo "golpe" (Quadro III). 


\section{Quadro III - Articulistas diversos.}

\begin{tabular}{|c|c|c|c|c|}
\hline Data & Pág. & Coluna/autor & Título & trecho \\
\hline 28.03 & p. 13 & $\begin{array}{l}\text { Paulo Guedes } \\
\text { economista }\end{array}$ & Tipos de golpes & $\begin{array}{l}\text { "E se uma 'operação mãos sujas' } \\
\text { sair da clandestinidade para virar } \\
\text { programa de governo e ocultar as } \\
\text { bases legais do impeachment?" }\end{array}$ \\
\hline 01.04 & p. 19 & $\begin{array}{l}\text { Paulo Nogueira } \\
\text { Batista Jr. - } \\
\text { economista }\end{array}$ & Golpe? & $\begin{array}{l}\text { "O impeachment é golpe? Não. O } \\
\text { afastamento da presidente da } \\
\text { República está previsto na } \\
\text { Constituição Federal. O } \\
\text { impeachment sem configuração de } \\
\text { crime de responsabilidade fiscal ou } \\
\text { de crime comum é golpe? Sim". }\end{array}$ \\
\hline 08.04 & p. 19 & $\begin{array}{l}\text { Nelson Motta } \\
\text { Escritor e crítico } \\
\text { musical }\end{array}$ & Cenário, roteiro e elenco & $\begin{array}{l}\text { "No sonho de Dilma não tem golpe, } \\
\text { não tem impeachment, nem } \\
\text { renúncia, nem novas eleições. Tudo } \\
\text { continua como está. Pior do que } \\
\text { nunca". }\end{array}$ \\
\hline 09.04 & p. 18 & $\begin{array}{l}\text { Guilherme Fiúza } \\
\text { escritor }\end{array}$ & $\begin{array}{l}\text { Governo oprimido, Constituição } \\
\text { golpista }\end{array}$ & $\begin{array}{l}\text { "Sabe qual é o novo bordão dos } \\
\text { denunciados do golpe contra a } \\
\text { clepto-democracia petista? Gritar } \\
\text { que os vazamentos da Lava-Jato são } \\
\text { seletivos". }\end{array}$ \\
\hline 15.04 & p. 19 & $\begin{array}{l}\text { Jorge Maranhão - } \\
\text { filósofo, do Inst. } \\
\text { Voz do Cidadão }\end{array}$ & A novilíngua petista & $\begin{array}{l}\text { "Golpe parlamentar: expressão } \\
\text { alardeada pelos petistas para se } \\
\text { colocar no papel de vítima com a } \\
\text { maior desfaçatez, quando o próprio } \\
\text { PT pediu impeachment setenta } \\
\text { vezes contra Sarney, Collor, Itamar } \\
\text { e FHC". }\end{array}$ \\
\hline 16.04 & p. 21 & $\begin{array}{l}\text { Cristovam } \\
\text { Buarque - senador, } \\
\text { votou pelo } \\
\text { impeachment de } \\
\text { Rousseff }\end{array}$ & Impeachment do modelo & $\begin{array}{l}\text { Uma das provas do fracasso dos } \\
\text { 'governos de esquerda' no Brasil é o } \\
\text { baixo nível do debate político, neste } \\
\text { grave momento de nossa história. } \\
\text { Nunca de discutiu tanto a política, } \\
\text { sem debater políticas: tudo se } \\
\text { resume à dicotomia 'tira Dilma' e 'é } \\
\text { golpe'. }\end{array}$ \\
\hline 23.04 & p. 2 & $\begin{array}{l}\text { Luiz Antonio } \\
\text { Novais - } \\
\text { jornalista/ col. } \\
\text { Conexão São } \\
\text { Paulo }\end{array}$ & Um passinho atrás & $\begin{array}{l}\text { "Pressionada a denunciar na ONU o } \\
\text { andamento de outro suposto golpe, a } \\
\text { presidente Dilma voou na quinta- } \\
\text { feira para NY e deixou em seu lugar } \\
\text { o vice Michel Temer - justamente } \\
\text { aquele a quem acusa de chefiar o } \\
\text { golpe". }\end{array}$ \\
\hline
\end{tabular}




\begin{tabular}{lllll}
$\mathbf{2 4 . 0 4}$ & p. 19 & $\begin{array}{l}\text { Cacá Diegues - } \\
\text { cineasta }\end{array}$ & Golpe com votos & $\begin{array}{l}\text { "A única vantagem nesse episódio é } \\
\text { a de constatar que as instituições } \\
\text { estão firmes e firmes devem } \\
\text { permanecer. Nada foi feito fora da } \\
\text { legalidade...". }\end{array}$ \\
\hline $\mathbf{2 5 . 0 4}$ & p. 6 & $\begin{array}{l}\text { Pedro Dória } \\
\text { jornalista } \\
\text { articulista }\end{array}$ & $\begin{array}{l}\text { A imprensa estrangeira não vê } \\
\text { golpe }\end{array}$ & $\begin{array}{l}\text { "A cobertura estrangeira é boa, } \\
\text { detalhista...e nenhum momento } \\
\text { compra a ideia de que há um golpe } \\
\text { em curso". }\end{array}$ \\
\hline
\end{tabular}

Na linha de frente da cobertura, porém, estão as notícias factuais do dia-a-dia. As hardnews, que suprem o leitor com as informações "duras" do cotidiano, narrativas abertas, ainda em seu desenrolar e geralmente com pouca ou nenhuma contextualização, seja pela falta de espaço e ou por pressão da hora do fechamento (deadline). São os fragmentos de informação a contribuir com o mosaico noticioso na formação de sentidos sobre os acontecimentos. A relevância das hardnews está justamente em "fornecer" os temas e, muitas vezes, as angulações a serem depuradas analiticamente pelos comentaristas da publicação (Quadro IV). Nestes casos, o jornal pautou entrevistas com personalidades de relevo da sociedade para contraditar o uso da expressão "golpe". Registre-se que as únicas matérias as quais citam explicitamente a referência a um "golpe" foram as manifestadas em reportagens envolvendo diretamente Dilma Rousseff em seus pronunciamentos públicos. O que ocorreu apenas em três ocasiões nas quais a expresidente afirmou estar sendo vítima de um processo golpista, sendo outras cinco entrevistas contrárias a sua tese. 
Quadro IV - Reportagens diversas hardnews.

\begin{tabular}{|c|c|c|c|c|}
\hline Data & Pág. & Coluna/autor & Título & trecho \\
\hline 23.03 & p. 3 & Reportagem & Dilma radicaliza discurso & $\begin{array}{l}\text { "Neste caso, não cabem meias } \\
\text { palavras: o que está em curso é um } \\
\text { golpe contra a democracia". }\end{array}$ \\
\hline 27.03 & p. 4 & $\begin{array}{l}\text { Entrevista pres. } \\
\text { OAB - Claudio } \\
\text { Lamachia }\end{array}$ & $\begin{array}{l}\text { Impeachment é o remédio } \\
\text { jurídico da nossa democracia }\end{array}$ & $\begin{array}{l}\text { "...Tanto não se está a falar de golpe } \\
\text { que o próprio Supremo Tribunal } \\
\text { Federal regulamentou o processo de } \\
\text { impeachment..." }\end{array}$ \\
\hline 27.03 & p. 8 & $\begin{array}{l}\text { Entrevista decano } \\
\text { do STF } \\
\text { Celso de Mello }\end{array}$ & $\begin{array}{l}\text { Decano do STF não vê golpe em } \\
\text { impeachment }\end{array}$ & $\begin{array}{l}\text { "O impeachment não pode ser } \\
\text { reduzido a um mero golpe (...) É um } \\
\text { instrumento previsto na } \\
\text { Constituição. }\end{array}$ \\
\hline 31.03 & p. 3 & $\begin{array}{l}\text { Reportagem com } \\
\text { Janaina Paschoal, } \\
\text { autora do pedido } \\
\text { de impeachment }\end{array}$ & Fomos vítimas de um golpe & $\begin{array}{l}\text { "Tenho visto vários cartazes } \\
\text { dizendo que o impeachment sem } \\
\text { crime é golpe. Essa frase é } \\
\text { verdadeira. Como eleitora e cidadã, } \\
\text { que estuda Direito, digo que nós } \\
\text { fomos vítimas de um golpe", afirma } \\
\text { a jurista... }\end{array}$ \\
\hline 31.03 & p. 4 & Reportagem & $\begin{array}{l}\text { É um processo golpista, afirma } \\
\text { Dilma }\end{array}$ & $\begin{array}{l}\text { "-Que processo é esse? É um } \\
\text { processo golpista - afirmou Dilma, } \\
\text { referindo-se ao pedido de } \\
\text { afastamento. } \\
\text { - Impeachment sem crime de } \\
\text { responsabilidade é o quê? É golpe, } \\
\text { disse Dilma." }\end{array}$ \\
\hline 21.04 & p. 1 & $\begin{array}{l}\text { Manchete do } \\
\text { jornal }\end{array}$ & $\begin{array}{l}\text { Ministros do STF: Dilma ofende } \\
\text { instituições ao falar em golpe }\end{array}$ & $\begin{array}{l}\text { "Decano Celso de Mello condena } \\
\text { 'gravíssimo equívoco' da presidente } \\
\text { (linha fina). }\end{array}$ \\
\hline 21.04 & p. 3 & Reportagem & É equívoco falar em golpe & $\begin{array}{l}\text { "Ministros do STF criticam } \\
\text { acusação de Dilma e dizem que o } \\
\text { processo segue regra definidas". } \\
\text { (linha fina) }\end{array}$ \\
\hline 23.04 & p. 5 & Reportagem & $\begin{array}{l}\text { Dilma fala em 'crise' na ONU e } \\
\text { em 'golpe' a jornalistas }\end{array}$ & $\begin{array}{l}\text { "Presidente critica ministros do STF } \\
\text { que contestaram tese de ilegalidades } \\
\text { no processo". }\end{array}$ \\
\hline
\end{tabular}


Acreditamos que a carga informativa despejada pelo jornal no embate golpe $\mathrm{x}$ impeachment no conjunto das edições pode demonstrar como se deu o arranjo editorial nesse espectro mais amplo da cobertura do acontecimento. A mesma intensidade com a qual O Globo dedicou para desqualificar o uso do termo "golpe" foi repetida nas coberturas de outros temas, não necessariamente ligados ao assunto do afastamento da presidente, mas indiretamente contribuindo para o seu desgaste. Foi assim nas abordagens de temas sobre corrupção no governo, com a Operação Lava-Jato, da Polícia Federal e levada a cabo pelo Ministério Público, tendo seu mote acusador central denúncias de desvio de recursos de empresas públicas e privadas para campanhas políticas e pessoas ligadas ao Partido dos Trabalhadores e de outras siglas partidárias.

São esses temas aqui assinalados como núcleos temáticos, ou os actantes. Desta forma, ao longo da cobertura nos dois meses analisados percebe-se que as reportagens relativas a tais núcleos funcionaram como forças auxiliares no enfraquecimento da presidente em seu cargo. Os núcleos temáticos, no caso, dizem respeito aos seguintes temas transformados em narrativas secundárias: os marqueteiros do PT, João e sua esposa Mônica Santana (presos pelo juiz Moro, delataram o recebimento de recursos em caixa dois para financiamento eleitoral), o sítio de Atibaia (que seria de propriedade de Lula num caso de ocultação de patrimônio), as delações dos empresários da construtora Andrade Gutierrez (sobre repasses para campanhas eleitorais petistas e outros favores a Lula), a delação do ex-senador Delcídio do Amaral (ex-PT) (que diz ter Lula e Dilma solicitado a ele interceder contra a Operação Lava-Jato) e, por fim, a crise econômica do país. Segundo O Globo, hiperbolicamente, tida como a maior da história.

Todas essas narrativas secundárias, ou micro-narrativas, por sua vez, têm um fio condutor comum a costurar todo o enredo: a Operação Lava-Jato. A rigor, também todos os acontecimentos mais significativos, principalmente os três episódios mais noticiados no período da amostragem desse levantamento - nomeação frustrada de Lula como chefe da Casa Civil do governo Dilma; as manifestações pelo impeachment, e a votação do impedimento pela Câmara -, têm a participação ou mesmo a interferência direta do Ministério Público ou das demais instâncias do Judiciário. E, assim como ocorreu na disputa semântica a respeito do termo "golpe", tais núcleos temáticos foram abordados, majoritariamente, sob o enfoque desfavorável ao governo de então e seu principal partido de sustentação (PT). 
No episódio das manifestações do "Fora Dilma", o jornal destinou 13 páginas de sua edição de 14 de março de 2016 para o tema, sendo que em nove delas o assunto foi o abre da página (Quadro V). A publicação destacou o volume de pessoas nas ruas, qualificou o evento como "maior protesto da História" do Brasil, abriu espaços para manifestantes "fantasiados" e salientou o apoio ao juiz Sérgio Moro, bem como à Operação Lava-Jato, e as críticas a Dilma e Lula. Também nesse caso, os articulistas forneceram o lastro argumentativo para o tom adotado das reportagens. Todos, sem exceção, elogiosos ao movimento das massas nas ruas.

O jornal, assim como vários outros veículos de imprensa, adotou a figura de linguagem da sinédoque, tipo de metonímia que substitui um termo por outro, ampliando-se ou reduzindo seu sentido. Como, por exemplo, nos títulos "Brasil vai às ruas...", "Brasil renuncia a Dilma", "A voz que ecoa das ruas" ou "um mar de gente". Pode-se dizer, que por trás do uso de tal recurso abriga-se uma metanarrativa a sugerir que todo o país era contrário a permanência de Rousseff na presidência.

Quadro V - Sobre as manifestações do Fora Dilma.

\begin{tabular}{|c|c|c|c|}
\hline Data & Pág. & título & Trecho \\
\hline 14.3 & capa & $\begin{array}{l}\text { Brasil vai às ruas contra Lula e } \\
\text { Dilma e a favor de Moro }\end{array}$ & $\begin{array}{l}\text { Protesto pacífico reuniu } 3,4 \text { milhões de pessoas em } 320 \\
\text { cidades de todos os estados e no Distrito Federal. }\end{array}$ \\
\hline 14.3 & p. 2 & $\begin{array}{l}\text { O Brasil renuncia a Dilma } \\
\text { (col. Ricardo Noblat) }\end{array}$ & $\begin{array}{l}\text { Uma vez lavado de certas impurezas de origem pelas } \\
\text { manifestações que marcaram o domingo, o pedido de } \\
\text { impeachment da presidente Dilma Rousseff espera a } \\
\text { última palavra do Supremo Tribunal Federal (STF) para } \\
\text { finalmente dar a partida na Câmara dos Deputados. }\end{array}$ \\
\hline 14.3 & p. 3 & A voz que ecoa das ruas & $\begin{array}{l}\text { Na maior manifestação política do país, protestos } \\
\text { contra o governo reúnem } 3,4 \text { milhões. }\end{array}$ \\
\hline 14.3 & p. 4 & $\begin{array}{l}\text { Em São Paulo, 1,4 milhão de } \\
\text { manifestantes }\end{array}$ & $\begin{array}{l}\text { No maior protesto da História, na Paulista, dez carros } \\
\text { de som e trios elétricos foram usados por } 40 \\
\text { movimentos. }\end{array}$ \\
\hline 14.3 & p. 6 & $\begin{array}{l}\text { Moro se diz "tocado" com apoio das } \\
\text { ruas }\end{array}$ & $\begin{array}{l}\text { Em todo o país, manifestantes elogiam a Lava-Jato e } \\
\text { usaram máscaras e camisetas com foto do juiz. }\end{array}$ \\
\hline 14.3 & p. 8 & $\begin{array}{l}\text { Irreverência marca protestos contra } \\
\text { Lula }\end{array}$ & $\begin{array}{l}\text { Ex-presidente inspirou manifestantes que, com muita } \\
\text { ironia, encheram as ruas e praças por todo o país. }\end{array}$ \\
\hline 14.3 & p. 9 & $\begin{array}{l}\text { Aliados admitem que protestos } \\
\text { fortalecem o impeachment }\end{array}$ & $\begin{array}{l}\text { Dilma diz que protestos mostram "maturidade" e elogia } \\
\text { tom pacífico }\end{array}$ \\
\hline
\end{tabular}

REU, Sorocaba, SP, v. 43, n. 1, p. 169 - 192, jun. 2017 


\begin{tabular}{llll}
$\mathbf{1 4 . 3}$ & p. 11 & $\begin{array}{l}\text { No Nordeste, grito contra Dilma e } \\
\text { Lula se amplia }\end{array}$ & $\begin{array}{l}\text { Recife teve maior manifestação da região, com 120 mil } \\
\text { pessoas, oito vezes mais que em março de 2015. }\end{array}$ \\
\hline $\mathbf{1 4 . 3}$ & p. 12 & As faces da manifestação & $\begin{array}{l}\text { Irreverência cobre o Brasil de verde e amarelo em } \\
\text { detalhes flagrados nas ruas }\end{array}$ \\
\hline $\mathbf{1 4 . 3}$ & p. 21 & $\begin{array}{l}\text { Um mar de gente (col. Paulo } \\
\text { Guedes) }\end{array}$ & $\begin{array}{l}\text { A voz das ruas: "Chega de corrupção", "Fora Dilma e } \\
\text { fora PT", "Sérgio Moro, herói da cidadania brasileira" e } \\
\text { "Lula na cadeia". }\end{array}$ \\
\hline
\end{tabular}

\section{Lula ministro}

Já quando da tentativa em nomear Lula como ministro ${ }^{3}$ da Casa Civil, o jornal dedicou 13 manchetes de alto de página na edição de 17 de março, dia posterior à tentativa da presidente Dilma em nomear o ex-presidente à sua equipe de governo (Quadro VI). Pode-se considerar que todas com viés negativo de abordagem (ver quadro). E, assim como em outros episódios, as reportagens vinham acompanhadas de textos dos comentaristas, em sua maioria, com as mesmas perspectivas de julgamento sobre o episódio. Em síntese, críticas ao governo e seus representantes, favoráveis ao Judiciário, Ministério Público e Polícia Federal.

\section{Quadro VI - A nomeação de Lula.}

\begin{tabular}{|c|c|c|c|}
\hline Data & Pág. & título & Trecho \\
\hline 17.3 & сара & Diálogo ameaça Dilma & $\begin{array}{l}\text { Investigado na Lava-Jato e sob ameaça de prisão, o ex- } \\
\text { presidente Lula voltou ontem ao governo, nomeado } \\
\text { ministro da Casa Civil pela presidente Dilma para } \\
\text { ganhar foro privilegiado no STF e escapar de decisões } \\
\text { do juiz de primeira instância Sérgio Moro. }\end{array}$ \\
\hline 17.3 & p. 3 & Ação contra a Justiça & $\begin{array}{l}\text { Horas depois de o retorno de Lula ao governo ser } \\
\text { confirmado, Sérgio Moro divulga gravações em que } \\
\text { Dilma diz ao ex-presidente que enviaria o termo de } \\
\text { posse com poder de impedir sua decisão; revelações } \\
\text { ensejam novos protestos e oposição exige renúncia. }\end{array}$ \\
\hline 17.3 & p. 4 & $\begin{array}{l}\text { Lula pede a Nelson Barbosa que } \\
\text { interceda na Receita Federal }\end{array}$ & $\begin{array}{l}\text { Ex-presidente se mostrou contrariado com apuração } \\
\text { sobre instituto. }\end{array}$ \\
\hline 17.3 & p. 5 & $\begin{array}{l}\text { "Temos uma Suprema Corte } \\
\text { acovardada" }\end{array}$ & $\begin{array}{l}\text { Em conversa com Dilma, Lula reclama de tribunais; ex- } \\
\text { presidente pede interferência em decisão do STF }\end{array}$ \\
\hline
\end{tabular}

\footnotetext{
${ }^{3}$ Caso nomeado ministro, o ex-presidente Lula contaria com foro privilegiado e não ser mais julgado pelo juiz de primeira instância da Vara de Curitiba, Sérgio Moro, mas sim pelo Supremo Tribunal Federal, o que, em tese, lhe garantiria mais tempo de tramitação das acusações.
} 


\begin{tabular}{|c|c|c|c|}
\hline 17.3 & p. 6 & $\begin{array}{l}\text { "Tô assustado com a República de } \\
\text { Curitiba" }\end{array}$ & $\begin{array}{l}\text { Desabafos, ataques, fofocas e articulações; os } \\
\text { principais trechos interceptados pela PF nas conversas } \\
\text { de Lula }\end{array}$ \\
\hline 7.3 & p. 7 & $\begin{array}{l}\text { Dilma nega obstrução e diz que vai } \\
\text { à Justiça }\end{array}$ & $\begin{array}{l}\text { Em nota, presidente afirma que enviou o termo de } \\
\text { posso porque poderia não comparecer ao evento. }\end{array}$ \\
\hline 7.3 & p. 8 & $\begin{array}{l}\text { Ruas explodem em protestos e } \\
\text { panelaços... }\end{array}$ & $\begin{array}{l}\text { Em } 15 \text { estados e no Distrito Federal, manifestantes } \\
\text { pedem renúncia de Dilma e reagem contra Lula. }\end{array}$ \\
\hline 7.3 & p. 9 & $\begin{array}{l}\text { Especialistas comentam grampo de } \\
\text { Lula }\end{array}$ & $\begin{array}{l}\text { Houve obstrução da Justiça por parte de Dilma? } \\
\text { O grampo e sua divulgação são legais? } \\
\text { O termo de posso evitaria uma eventual prisão de Lula? }\end{array}$ \\
\hline 7.3 & p. 11 & $\begin{array}{l}\mathrm{Na} \text { Casa Civil, Lula assumiria papel } \\
\text { de protagonista no governo }\end{array}$ & $\begin{array}{l}\text { Se tomar posse, ex-presidente terá foro privilegiado e } \\
\text { só poderá ser julgado pelo STF. }\end{array}$ \\
\hline 7.3 & p. 12 & $\begin{array}{l}\text { Comissão do impeachment deve ser } \\
\text { criada hoje }\end{array}$ & $\begin{array}{l}\text { STF mantém regras para tramitação do processo, e } \\
\text { Cunha apressa escolha de chapa e eleição de deputados. }\end{array}$ \\
\hline 7.3 & p. 18 & $\begin{array}{l}\text { Lula e Dilma apostam tudo para } \\
\text { sobreviver (editorial/Opinião) }\end{array}$ & $\begin{array}{l}\text { A presidente, seu mentor e criador se juntam a fim de } \\
\text { afastar o risco de impeachment, recuperar a economia, } \\
\text { e tudo sem desagradar aos movimentos sociais. Tarefa } \\
\text { difícil. }\end{array}$ \\
\hline 7.3 & p. 19 & Ministro Lula e o foro privilegiado & $\begin{array}{l}\text { Pode algum cidadão escolher o juiz que o julgará e o } \\
\text { membro do Ministério Público que o investigará e o } \\
\text { denunciará? A resposta é desenganadamente negativa. }\end{array}$ \\
\hline 7.3 & p. 21 & Paralisia (cad. Economia) & $\begin{array}{l}\text { Gravações de conversas entre Lula e Dilma mergulham } \\
\text { economia em incerteza inédita. }\end{array}$ \\
\hline 7.3 & p. 22 & $\begin{array}{l}\text { O fim do caminho } \\
\text { (col. Míriam Leitão) }\end{array}$ & $\begin{array}{l}\text { O governo tinha expectativa de que a nomeação do ex- } \\
\text { presidente Lula fosse reduzir a crise e ela atingiu o seu } \\
\text { ponto máximo com o conhecimento dado à opinião } \\
\text { pública do teor das conversas do agora ministro Lula. }\end{array}$ \\
\hline
\end{tabular}




\section{Votação do impeachment}

$\mathrm{Na}$ cobertura feita para o dia da votação do impeachment, O Globo trouxe as negociações com as bases parlamentares tanto por parte de Dilma quanto pelo lado de Temer. No caso da primeira, atrelando seus movimentos ao clientelismo e/ou fisiologismo enquanto na representação da oposição, as manobras de convencimento recebiam a designação mais genérica de negociações (Quadro VII). Fez previsões sobre a queda de Dilma e deu luz às ironias lançadas pelos defensores de prisão para o ex-presidente Lula.

Quadro VII - Sobre a votação do impeachment.

\begin{tabular}{|c|c|c|c|}
\hline Data & Pág. & Título & Trecho \\
\hline 17.4 & Capa & $\begin{array}{l}\text { Dilma e Temer negociam } \\
\text { pessoalmente cada voto }\end{array}$ & $\begin{array}{l}\text { Câmara começa hoje a decidir destino da presidente } 24 \\
\text { anos depois do afastamento de Collor e } 13 \text { anos após o } \\
\text { PT chegar ao poder. }\end{array}$ \\
\hline 17.4 & & $\mathrm{O}$ duelo pela presidência & $\begin{array}{l}\text { Câmara decide hoje se autoriza abertura do processo } \\
\text { contra Dilma, } 24 \text { anos após o impeachment de Collor }\end{array}$ \\
\hline 17.4 & p. 4 & $\begin{array}{l}\text { Nomeações extras na véspera do } \\
\text { Dia D }\end{array}$ & $\begin{array}{l}\text { Oposição denuncia ao MP edição extra do Diário } \\
\text { Oficial }\end{array}$ \\
\hline 17.4 & p. 4 & $\begin{array}{l}\text { Hora da decisão } \\
\text { (col. Merval Pereira) }\end{array}$ & $\begin{array}{l}\text { Se a tendência detectada nas pesquisas feitas de } \\
\text { diversas maneiras - consulta direta aos interessados em } \\
\text { projeções baseadas em sofisticados cálculos } \\
\text { matemáticos - for confirmada, começa hoje uma } \\
\text { transição de poder que deveria ter sido iniciada na } \\
\text { eleição presidencial de } 2014 \text {. }\end{array}$ \\
\hline 17.4 & p. 5 & $\begin{array}{l}\text { Partidos começam a punir } \\
\text { deputados dissidentes }\end{array}$ & $\begin{array}{l}\text { PP diz que apenas } 5 \text { dos seus parlamentares votarão } \\
\text { pró-Dilma; Garotinho busca votos para a presidente }\end{array}$ \\
\hline 17.4 & p. 6 & $\begin{array}{l}\text { O que você precisa saber sobre o } \\
\text { impeachment }\end{array}$ & $\begin{array}{l}\text { A Câmara dos Deputados vota hoje o pedido de } \\
\text { abertura de processo de impeachment da presidente } \\
\text { Dilma Rousseff. O Globo responde a algumas das } \\
\text { perguntas e dúvidas mais frequentes sobre o processo } \\
\text { que pode se estender até novembro no Senado Federal. }\end{array}$ \\
\hline 17.4 & p. 8 & $\begin{array}{l}\text { Eliseu Padilha monitora votos em } \\
\text { tempo real }\end{array}$ & $\begin{array}{l}\text { Em Q.G. de Temer, planilha registra desde dezembro } \\
\text { apoios a processo. }\end{array}$ \\
\hline 17.4 & p. 9 & $\begin{array}{l}\text { Lula articula vale-tudo em busca de } \\
\text { apoio }\end{array}$ & $\begin{array}{l}\text { Em bunker de Dilma, governistas oferecem cargos e } \\
\text { cobram alianças }\end{array}$ \\
\hline 17.4 & p. 10 & & \\
\hline
\end{tabular}

REU, Sorocaba, SP, v. 43, n. 1, p. 169 - 192, jun. 2017 


\begin{tabular}{|c|c|c|c|}
\hline & & $\begin{array}{l}\text { Dilma: o declínio de uma presidente } \\
\text { por acaso }\end{array}$ & $\begin{array}{l}\text { Para aliados, principais erros do governo foram não } \\
\text { honrar compromissos nem fazer política }\end{array}$ \\
\hline 17.4 & p. 11 & $\begin{array}{l}\text { Na porta de hotel de Lula, briga e } \\
\text { mortadelão }\end{array}$ & $\begin{array}{l}\text { Grupos já chegam a Brasília para manifestações contra } \\
\text { e a favor do afastamento de Dilma }\end{array}$ \\
\hline 17.4 & p. 24 & As estrelas cadentes do PT & $\begin{array}{l}\text { Saída de petistas históricos do cenário político após } \\
\text { escândalo enfraquece legenda }\end{array}$ \\
\hline 17.4 & p. 25 & $\begin{array}{l}\text { Entre a impopularidade de Dilma e } \\
\text { a desconfiança sobre Temer }\end{array}$ & $\begin{array}{l}\text { Cientistas políticos analisam cenários com e sem } \\
\text { afastamento, e dizem não haver solução mágica para } \\
\text { crise. }\end{array}$ \\
\hline 17.4 & p. 40 & $\begin{array}{l}\text { A soma das tempestades (col. } \\
\text { Míriam Leitão) }\end{array}$ & $\begin{array}{l}\text { O que nos trouxe até aqui foi a economia. A luta contra } \\
\text { a corrupção não explica o que se passa no país, já que } \\
\text { os dois lados que se enfrentam no plenário da Câmara } \\
\text { há envolvidos na Operação Lava-Jato. Não há na lei do } \\
\text { impeachment nada que puna a má gestão econômica, } \\
\text { mas nenhum governo resiste ao trio inflação alta, } \\
\text { recessão profunda e colapso fiscal. }\end{array}$ \\
\hline
\end{tabular}

\section{Considerações finais}

A tessitura da trama do acontecimento do impeachment de Rousseff foi tecida, nos meses preliminares à votação do pedido de impedimento pela Câmara dos Deputados, por uma série de narrativas secundárias, que analisadas num contexto mais amplo da publicação, apontam para um flagrante desequilíbrio editorial em prol de um lado da intriga - o dos promotores do afastamento da presidente e da ascensão do vice-presidente Temer ao cargo máximo do Executivo.

O emaranhado de fios narrativos da trama revela alguns nós do enredo, que permitem vislumbrar a participação decisiva de alguns atores, como o Judiciário, e seu braço auxiliar, o Ministério Público (ou o contrário). Em alguns momentos, a participação foi diretamente promovida a "atrapalhar" os movimentos da então presidente, como no episódio polêmico da divulgação de escutas telefônicas entre Lula e Dilma por parte do juiz Moro. Iniciativa que resultou numa grande manifestação contra o ex-presidente e a mandatária da República, assim como justificou ação do ministro Gilmar Mendes, do Supremo Tribunal Federal, a conceder uma liminar contra a posse de Lula como ministro-chefe da Casa Civil.

Outro aspecto a denotar uma tendência a enfraquecer a imagem do governo Dilma no noticiário do jornal foi a publicização das ocorrências no mundo econômico, afetadas pela 
instabilidade política do momento. Conforme as edições, encontra-se uma correlação editorial pela qual sempre que as matérias de política eram contrárias ao governo e seus satélites políticos, as páginas de economia registravam os humores positivos do mercado financeiro. E vice-versa: "Dólar cai mais 1,12\% e fecha a R \$ 3.698", título da reportagem de 10 de março, página 21, cuja linha-fina dizia: "Com crise no governo, cotação recua a patamar de setembro, antes da perda do grau de investimento". Ou com as matérias: "Com delação de Delcídio, Bolsa tem maior alta desde 2009: 5,12\%" (4 de março, p.29); "Euforia a jato. Com depoimento do expresidente Lula, Bolsa de São Paulo sobe 4\% e dólar recua 1,1\%, a R \$ 3,761" (5 de março, p. 23), "Com rumor sobre Lula, dólar sobe 1,72\%. Moeda americana é cotada a US\$ 3,652. Manifestações não ajudaram a Bolsa, que teve queda de 1,55\%" (15 de março, p. 19) ou "Efeito dominó. Queda da produção e alta no desemprego derrubam arrecadação e dificultam ajuste fiscal", manchete do caderno de economia de 19 de março, abrigada sob o chapéu "Lava-Jato no Planalto".

Mais um indicador do desequilíbrio editorial pode ser verificado com os levantamentos feitos pelo website Manchetômetro (www.manchetometro.com.br), mantido pelo Laboratório de Estudos de Mídia e Esfera Pública (LEMEP), do Instituto de Estudos Sociais e Políticos (IESP) da Universidade do Estado do Rio de Janeiro (UERJ). Segundo o sítio do laboratório, a metodologia do Manchetômetro é a análise de valências que, em síntese, busca responder se o tema ou personagens das reportagens têm "valências" positivas, negativas, neutras e ambivalentes. No caso do período desta investigação, conforme o Manchetômetro ${ }^{4}$ (Gráfico 1), os índices de valência para Dilma Rousseff, Lula Inácio Lula da Silva e Sérgio Moro foram os seguintes:

\footnotetext{
${ }^{4} \mathrm{O}$ Manchetômetro, por questões técnicas, não apresenta as notícias positivas na data deste trabalho, apenas as neutras e negativas. 


\section{Gráfico 1 - Personagens LULA, DILMA ROUSSEFF e SÉRGIO MORO}

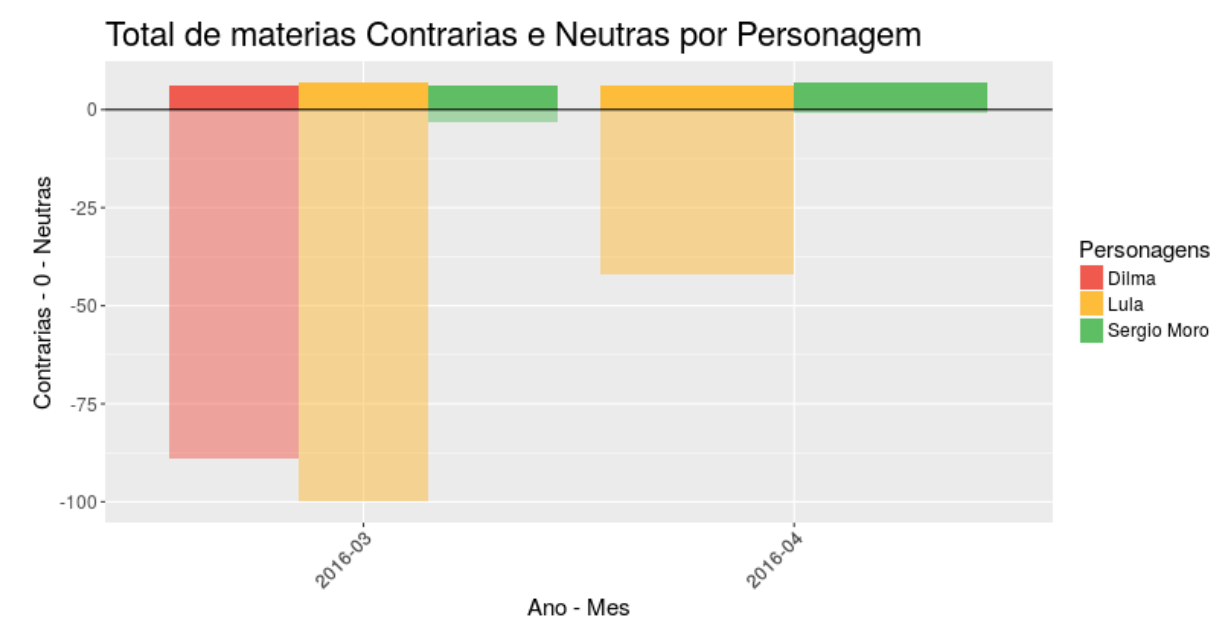

Fonte: Disponível em:<www.manchetometro.com.br>. Acesso em: 10 maio 2017.

Pelo levantamento, é perceptível a falta de equidade no comportamento do jornal diante do acontecimento do impeachment. Se adotarmos como válida a analogia à "blitzkrieg" alemã nesse "jornalismo de guerra" praticado por O Globo, podemos considerar que a análise da cobertura revelou a ofensiva da publicação em salientar suas intencionalidades como também intensifica seus "ataques" em determinados momentos do processo narrativo. Como nas ofensivas alemãs, que penetravam nas linhas inimigas e desestruturavam suas linhas defensivas, o "jornalismo de guerra" de O Globo, cuja linha de frente, ou artilharia, fez-se valer por uma espécie de alinhamento à Operação Lava-Jato e seus "soldados", estejam no Ministério Público ou no Judiciário propriamente dito. De tal forma que, os "ataques" ao governo deposto vieram pelos flancos da política, mas de certo modo pode-se considerar que a Operação Lava-Jato rompeu a linha defensiva do governo anterior, com seu arsenal jurídico-punitivo que impactou os cotidianos político e econômico do país, dificultando as manobras de reação dos adversários. Ressalte-se, em conclusão, que esta reflexão tem caráter exploratório, abrindo-se a várias e oportunas reeleituras. 


\begin{abstract}
O que espero dos historiadores da difícil história imediata, inclusive dos jornalistas, que, se fizerem bem seu ofício, são verdadeiros historiadores da história imediata, são quatro atitudes: ler o presente, o acontecimento, com uma profundidade histórica suficiente e pertinente; manifestar quanto a suas fontes o espírito crítico de todos os historiadores segundo os métodos adaptados a suas fontes; não se contentar em descrever e contar, mas esforçar-se para explicar, e tentar hierarquizar os fatos, distinguir o incidente do fato significativo e importante, fazer do acontecimento aquilo que permitirá aos historiadores do passado reconhecê-lo como outro, mas também integrá-lo numa longa duração e numa problemática na qual todos os historiadores de ontem e de hoje, de outrora e do imediato, se reúnam (LE GOFF apud CHAUVEAU; TÉTART, 1999, p. 102).
\end{abstract}

\title{
Referências
}

BLOG DO ALVORADA. Prova do jornalismo de guerra praticado pela Globo. Disponível em: <http://dilma.com.br/prova-do-jornalismo-de-guerra-praticado-pela-globo/>. Acesso em: 25 maio 2017.

BENTES, Ivana. Mídia brasileira construiu narrativa novelizada do impeachment, 2016. Disponível em: <https://theintercept.com/2016/09/01/midia-brasileira-construiu-narrativanovelizada-do-impeachment/>. Acesso em: 15 maio 2017.

BOBBIO, Norberto, MATTEUCCI, Nicola, PASQUINO, Gianfranco. Dicionário de Política. Brasília: UNB, 2003. 1. CD-ROM. Produzido Imprensa Oficial de São Paulo.

CHAUVEAU, Agnes; TÉTART, Philipe. Questões para a história do presente. São Paulo: Edusc, 1999.

DIJK, Teun A. Van. Discurso e poder. São Paulo: Contexto, 2008.

El País (Argentina). El editor de Clarín aseguró que eldiariohizo "periodismo de guerra" contra elkircherismo. 19 julho 2016. Disponível em:

<http://www.elpaisdigital.com.ar/contenido/clarn-hizo-periodismo-de-guerra-contra-elkirchnerismo/371>. Acesso em: 16 maio 2017.

KOSELLECK, Reinhart. Futuro passado. Contribuição à semântica dos tempos históricos. Rio de Janeiro: Contraponto, Editora Puc-RJ, 2006.

OLIVEIRA, Hebe Maria Gonçalvez de. A construção do impeachment de Dilma Rousseff pela mídia brasileira comercial na cobertura das manifestações de rua. In: ENCONTRO REGIONAL SUL DE HISTÓRIA DA MÍDIA - Alcar Sul, 6., Ponta Grossa, 2016. [Anais...] Universidade Estadual de Ponta Grossa (PR), 2016.

MOTTA, Luiz Gonzaga. Notícias do Fantástico. São Leopoldo: Unisinos, 2006.

MOTTA, Luiz Gonzaga. Análise pragmática da narrativa jornalística. In: LAGO, Cláudia; BENETTI, Márcia (Orgs.). Metodologia de pesquisa em jornalismo. Petrópolis: Vozes, 2007. 
MOTTA, Luiz Gonzaga. Enquadramentos lúdico-dramáticos no jornalismo: mapas culturais para organizar narrativamente os conflitos políticos. In: BIROLLI, Flávia; MIGUEL, Luiz Felipe (Orgs). Mídia, representação e democracia. São Paulo: Hucitec, 2010.

REUTER, Yves. A análise da narrativa: o texto, a ficção e a narração. Rio de Janeiro: Difel, 2007.

ROUSSEFF, Dilma. A prova do "jornalismo de guerra" praticado pela Globo. 18 abril 2017. Disponível em: <http://dilma.com.br/prova-do-jornalismo-de-guerra-praticado-pelaglobo>. Acesso em: 15 de maio 2017.

THOMPSON, John B. Ideologia e cultura moderna. Petrópolis: Vozes, 2009.

Eduardo Luiz Correia - Universidade Municipal de São Caetano do Sul - USCS. FiamFaam Centro Universitário. São Paulo | SP | Brasil. Contato: eduardocorreia67@gmail.com

Artigo recebido em maio de 2017 e aprovado em junho de 2017. 